\title{
Convergence, Adaptation, and Constraint
}

\section{Citation}

Losos, Jonathan B. 2011. Convergence, adaptation, and constraint. Evolution 65(7): 1827-1840.

\section{Published Version}

doi:10.1111/j.1558-5646.2011.01289.x

\section{Permanent link}

http://nrs.harvard.edu/urn-3:HUL.InstRepos:9938750

\section{Terms of Use}

This article was downloaded from Harvard University's DASH repository, and is made available under the terms and conditions applicable to Open Access Policy Articles, as set forth at http:// nrs.harvard.edu/urn-3:HUL.InstRepos:dash.current.terms-of-use\#OAP

\section{Share Your Story}

The Harvard community has made this article openly available.

Please share how this access benefits you. Submit a story.

\section{Accessibility}


Convergence, Adaptation and Constraint

Jonathan B. Losos

Museum of Comparative Zoology

Harvard University 26 Oxford St.

Cambridge, MA 02138

jlosos@oeb.harvard.edu 


\begin{abstract}
$\underline{\text { Abstract }}$
Convergent evolution of similar phenotypic features in similar environmental contexts has long been taken as evidence of adaptation. Nonetheless, recent conceptual and empirical developments in many fields have led to a proliferation of ideas about the relationship between convergence and adaptation. Despite criticism from some systematically-minded biologists, I reaffirm that convergence in taxa occupying similar selective environments often is the result of natural selection. However, convergent evolution of a trait in a particular environment can occur for reasons other than selection on that trait in that environment, and species can respond to similar selective pressures by evolving non-convergent adaptations. For these reasons, studies of convergence should be coupled with other methods - such as direct measurements of selection or investigations of the functional correlates of trait evolution - to test hypotheses of adaptation. The independent acquisition of similar phenotypes by the same genetic or developmental pathway has been suggested as evidence of constraints on adaptation, a view widely repeated as genomic studies have documented phenotypic convergenc resulting from change in the same genes, sometimes even by the same mutation. Contrary to some claims, convergence by changes in the same genes is not necessarily evidence of constraint, but rather suggests hypotheses that can test the relative roles of constraint and selection in directing phenotypic evolution.
\end{abstract}


“...we can clearly understand why analogical or adaptive character, although of the utmost importance to the welfare of the being, are almost valueless to the systematist. For animals, belonging to two most distinct lines of descent, may readily become adapted to similar conditions, and thus assume a close external resemblance..."

Charles Darwin (1859, p. 427).

Convergent evolution - the independent evolution of similar features in different evolutionary lineages - is a common, perhaps ubiquitous (Conway Morris, 2003, 2009, 2010), phenomenon, yet one whose interpretation is not clearcut. Many see in convergent evolution the unfettered ability of natural selection to produce optimal solutions to problems repeatedly posed by the environment. By contrast, others see in it constraints on the evolutionary process resulting from biases in the production of phenotypic variation; because evolution requires such variation, any process that limits the range of available variation will make the repeated evolution of similar features more likely.

The last few years have seen an explosion of research into the genetic basis of convergent evolution, with many studies finding that convergent phenotypes have been produced through similar changes at the genetic level, but others discovering convergent phenotypes resulting from different genetic changes. These studies speak to the adaptationist and constraint perspectives on convergent evolution and address the more fundamental question about the predictability of evolutionary change. More generally, convergent evolution has long been taken as evidence of adaptation, but some recent workers have questioned the ability of evolutionary biologists to infer the operation of natural selection from phylogenetic pattern.

In this review, I aim to discuss what convergence can - and cannot- tell us about evolutionary diversification, focusing on the possible explanations for convergent evolution, as well as discussing when adaptive evolution by multiple lineages experiencing the same selective environment might not lead to convergent outcomes. In addition, I will discuss the extent to which understanding the adaptive nature of phenotypic convergence is affected by knowledge of whether it is driven by convergent or divergent changes at the genetic level.

\section{What Can We Infer From the Existence of Convergence?}

Throughout the history of evolutionary biology, phenotypic similarity of distantly related taxa that occur in similar environments has been considered strong evidence that natural selection has produced evolutionary adaptation (e.g., Simpson, 1953; Mayr, 1963; Endler, 1986; Harvey and Pagel, 1989; Schluter, 2000; Conway Morris, 2003; throughout this paper, I broadly define "environment" as the sum of extrinsic potential selective factors encountered by a population or species, including habitat, climate, and sympatric species, among many others). The rationale for this assumption is straightforward: what process other than natural selection could lead fast-swimming aquatic animals such as sharks, tunas, ichthyosaurs and dolphins to evolve a streamlined body form? How, other than natural selection, could we account for the phenotypic similarity of distantly-related bipedal rodents from the deserts of North America and Asia, of nectar-feeding birds from different families in the Old and New Worlds, or of prickly plants in the Euphorbiaceae and Cactaceae from deserts around the world?

The advent of phylogenetic tree thinking in the early 1980's made explicit what was sometimes only implicit in the work of earlier evolutionary biologists: convergent evolution is 
phenotypic similarity that is independently derived in two or more lineages, rather than similarity resulting from inheritance from a common ancestor (this definition includes what is sometimes referred to as "parallel evolution," a topic to which I return later in this essay). Recognizing such derived similarity, of course, requires a phylogenetic perspective (Eldredge and Cracraft, 1980; Lauder, 1981; Ridley, 1983). This realization in turn led to the development of statistical methods that quantitatively test whether taxa occupying similar environmental conditions tend to evolve in similar ways (Gittleman, 1981; Ridley, 1983; Felsenstein, 1985; Huey and Bennett, 1987). The development of these phylogenetic comparative methods has become a growth industry, with new approaches, applications and even entirely novel methods appearing with increasing regularity (e.g., Carvalho et al., 2006; Ives et al., 2007; Revell et al., 2007a; Hansen et al., 2008; reviewed in Felsenstein, 2004; Garland et al., 2005). Journals of all sorts are replete with phylogenetically informed analyses; indeed, it is nearly impossible to publish a comparative study without taking a phylogenetic approach.

Long before this phylogenetic renaissance, however, evolutionary biologists were aware that comparative methods were not a foolproof means of identifying adaptations. Quite the contrary, comparative studies can be stymied by a number of issues that are as problematic today as they were decades ago. Moreover, advances in phylogenetics and functional morphology have added new wrinkles to the interpretation of comparative patterns. In addition, a backlash has emerged, making the bold claim that comparative data, even in a phylogenetic context, are of little use in the identification of evolutionary adaptation. Finally, the genomic revolution has led to the discovery of many new cases of convergent evolution, and has rekindled debate about the extent to which convergence is indicative of adaptation or constraint. My goal in this essay is to review all of these points with the aim of clarifying what convergence can and cannot tell us about adaptation and the evolutionary process.

\section{Convergent Evolution Can Occur For Reasons Other than Adaptive Evolution to Similar} Environments

Convergent evolution can occur for reasons unrelated to adaptation and natural selection. For example, random evolutionary change can cause species to become more similar to each other than were their ancestors. Stayton (2008) demonstrated that rates of convergence can be quite high in circumstances in which clades are diversifying under the influence only of genetic drift (Fig. 1).

In addition, shared biases in the production of variation, commonly called constraints, can lead to convergence. If the possible variants that can be produced are limited, then unrelated species are likely to produce the same variations, which may then become fixed in the population by genetic drift (or by selection; see below). This is easily seen in the evolution of DNA. Because only four possible states exist for a given nucleotide position, the probability that distantly related taxa will independently acquire the same change by chance is relatively high.

Developmental processes have long been seen as a source of constraint (Maynard Smith et al., 1985). If, for whatever reason, some changes in the developmental process are easier to accomplish than others, then the potential variation in a population will be biased toward those changes; as a result, evolution is most likely to proceed in that direction, either due to selection or random drift. Consequently, if taxa share the same developmental system (and thus the same constraints), they will be predisposed to evolve in the same way, producing convergent evolution. For example, in salamanders, the number of digits on the limbs is determined in part by the number of cells in the limb bud. Evolutionary changes that decreased the number of 
cells - such as decrease in overall body size or increase in cell size - have resulted in convergent reduction in digit number from five to four in many species (Alberch and Gale, 1985; Wake, 1991; see discussion in Reeve and Sherman, 1993; Amundson, 2001; Autumn et al., 2002). Wake (1991) and Jaekel and Wake (2007) provide many other similar examples from salamanders.

Shared patterns of genetic correlation can similarly bias the production of phenotypic variation and thus channel evolution in certain directions. This idea has been formalized as the idea that evolution may proceed most readily along the lines of least genetic resistance (Stebbins, 1974; Futuyma et al., 1993; Schluter, 1996); species with similar genetic correlations will tend to evolve in similar ways. Shared pleiotropic or epistatic effects likewise can cause convergence (Leroi et al., 1994). Clearly, convergent evolution can occur for many reasons unrelated to adaptation to similar selective conditions.

Thus, convergence per se is not indicative of adaptation. Rather, it is the occurrence of convergent evolution in taxa that experience similar selective environments that has been taken as evidence of the operation of natural selection. But is the argument absolute? Given that convergence can occur for reasons unrelated to natural selection, could a match between phenotype and environment evolve convergently without natural selection operating in the same way-- favoring similar traits in similar environments - in each instance?

Such convergence could occur in three ways:

1. As a coincidence - If traits evolve convergently for reasons unrelated to natural selection, then we shouldn't expect a correlation to exist between possession of the trait and occurrence in a particular selective environment (Pagel, 1994). However, it is possible that if a trait evolves convergently in multiple taxa for reasons unrelated to natural selection, just by chance the taxa all may occupy the same selective environment. Statistical tests, conducted in a phylogenetic framework, can assess whether an association between evolution of similar features and selective condition is statistically significant, but, of course, we accept the possibility that $5 \%$ of the time, incorrectly significant results will occur by chance. To some, the possibility that convergent evolution of similar traits in similar environments could occur coincidentally is enough to cast serious doubt on the comparative approach to identifying adaptation; not surprisingly, these workers reject the application of probabilistic thinking to historical evolutionary analyses (Kluge, 2005). Statistical approaches, however, are used in all other sciences, and the suggestion that these approaches are not applicable to historical evolutionary events does not withstand scrutiny (Felsenstein, 2004). Of course, in a hypothetico-deductive framework, a significant result invites further investigation (as described below), which ought to reveal mistaken support for an adaptation hypothesis.

2. Adaptation versus exaptation - A feature may confer high fitness in a particular environment, but may have evolved initially for another reason. As a result, two species may exhibit similar phenotypes while occupying similar selective environments, even if one or both did not evolve the feature as an adaptation for using that environment. This is the distinction between adaptation and exaptation (Gould and Vrba, 1982): an adaptation is a feature that evolved in response to natural selection in the environment in which it currently occurs, whereas an exaptation provides enhanced fitness in an environment, but did not originally evolve in response to natural selection in that environment. In the case of convergent exaptations, natural selection is still involved in favoring the feature in its current selective environment, even if it did not build the feature in response to those selective conditions (an unresolved question is whether adaptation usually plays a role in the initial evolution of exapations; Gould [2002] and Donoghue [2005] thought 
that exaptations may often initially evolve non-adaptively, whereas Arnold [1994] suggested that most such traits likely had an adaptive origin, on the grounds that if the traits arose nonadaptively, they would be unlikely to have much functional utility.).

3. Correlated response to selection on another character-If taxa share similar constraints, then selection on similar traits in multiple taxa may lead to similar correlated responses. For example, occupation of a particular habitat may lead to the evolution of small size; if smaller size is achieved through paedomorphosis, then other paedomorphic features, such as reduction in digit number or webbed feet, may also evolve convergently in the same habitat. Although natural selection would still have driven this evolution, we might incorrectly identify the target of selection as a trait other than body size. In this way, constraints and natural selection can interact to produce phenotype-environment correlations.

In summary, convergent evolution can occur even in the absence of natural selection favoring the convergent trait. Except for statistical accidents, such convergence would not be expected to be associated with occupation of a particular selective environment. However, for several reasons, natural selection can drive such a correlation, even if the trait in question did not always evolve because it is advantageous in that selective context.

\section{Testing the Adaptive Nature of Convergent Evolution}

Given the possibility that phenotypes may evolve convergently in similar environments even if not directly favored by natural selection, how can we further test the adaptation hypothesis?

\section{Measurements of Natural Selection}

One possibility is to directly measure selection in natural populations to see if the trait actually is favored; in this way, for example, one can determine whether the trait under question is the actual the target of selection (Lande and Arnold, 1983). This approach tests one component of an adaptation hypothesis, that a trait is beneficial in its current environment, in which case it would be an aptation in the terminology of Gould and Vrba (1982).

Aptations could be adaptations or exaptations. To distinguish between these hypotheses, researchers need to go one step further by attempting to recreate the original conditions in which a trait evolved, thus testing the role of selection in the evolutionary origin of the trait. To the extent that ancestral conditions can be correctly recreated, both in the focal population and the environmental setting ${ }^{1}$, this approach can be informative. Such studies can measure selection in these recreated environments, but longer-term microevolutionary experiments provide an even better test, because they investigate not only patterns of selection, but also evolutionary response.

\footnotetext{
${ }^{1}$ Some have pointed out that aspects of the external environment are not phylogenetically heritable traits, and thus their existence for ancestral populations cannot be inferred using phylogenetic methods. Thus, for example, even if all members of a clade are preyed upon by a particular predator, it would not necessarily follow that their ancestor also encountered the same predator (Grandcolas and D'Haese, 2003). This view has merit. Certainly, researchers need to justify assumptions about ancestral conditions, either by substantiating the use of phylogenetic inferences or by bringing in ancillary information to infer ancestral environmental conditions. In some cases, confident phylogenetic inference about the environmental context in which a trait evolved may not be possible. On the other hand, many of the selective factors that researchers study in the context of adaptational studies are features that involve behavior and habitat choice, such as the selection of particular prey types or use of certain habitats. These features are aspects of organismal biology and are potentially transmitted from ancestral to descendant species.
} 
Undoubtedly the best known example of this approach concerns adaptive response to the presence of predators in Trinidadian guppies. Endler (1980), noting that guppies in predator-free parts of streams are more colorful than those that occur in the presence of predators, simulated the colonization of predator-free habitats by moving guppies upstream from pools with predators to pools lacking them; as predicted, the predator-free populations rapidly evolved to be more colorful (see Reznick and Ghalambor [2005] for similar studies on other aspects of guppy life history adaptation). Studies of a similar nature are increasingly common in laboratory microbial and viral evolution experiments and in studies exploring the evolution of molecular function (reviewed in Poelwijk et al., 2007; Kassen, 2009; Wichman and Brown, 2010), although the studies often recreate the internal genetic environment (i.e., allelic states at other genes), rather than the external environment.

Overall, then, measurements of selection may be able to bolster convergence-inspired hypotheses of adaptation, but distinguishing adaptive from exaptive origins may be difficult without attempts to re-create ancestral environmental conditions; the ability to confidently infer ancestral conditions may make the latter approach difficult in many cases.

\section{Studies on the Functional Consequences of Trait Evolution}

Selection does not actually operate on traits themselves, but on their functional consequences (Arnold, 1983). One variant will be favored over another if it confers some enhanced capability - faster running speed, increased energetic efficiency, enhanced attractiveness to members of the opposite sex - that in turn leads to greater evolutionary fitness by increasing survival, mating success, or fecundity.

Thus, another test of a hypothesis of aptation is to investigate whether the trait actually produces the expected increased functional capability, and, if so, whether increased ability leads to an increase in some aspect of fitness. Much such work occurs in the fields of biomechanics and physiology, which investigate questions such as whether wing shape affects aerodynamic performance, toepads enhance clinging ability, cuticular secretions inhibit dehydration and so on. Indeed, in many cases, hypothesized functional relationships do exist: longer legs do allow lizards to run faster; wing shape affects speed and maneuverability in birds, bats, and insects; and leaf shape affects $\mathrm{CO}_{2}$ uptake and water loss in plants, to name just a few (e.g., Hildebrand et al., 1985; Wainwright and Reilly, 1994; Reich et al., 1997).

On the other hand, functional studies can also disprove an adaptive hypothesis: even taxa that are phenotypically similar may differ substantially in functional capacities. For example, tree-like forms - tall plants that branch well above the ground and have a single thickened trunk - have evolved many times in plant history, but this morphology has been achieved in radically different ways in different lineages (Donoghue, 2005). Functional analysis of these different morphologies indicates that not all of these forms could have existed in the way we think of trees today. For example, prehistoric lycophyte trees lacked secondary phloem and a bifacial cambium and thus would have had difficulty maintaining a tall structure for very long. For this reason, the tree-like morphology of these plants probably arose late in the life cycle during reproduction, much like a plant inflorescence (Donoghue, 2005). Similarly, webbed feed in salamanders do not always provide a functional advantage; some species have the ability to cling to smooth, wet surfaces, but many webbed salamander species do not (Jaekel and Wake, 2007). In both examples, convergent phenotypes do not produce convergent functional capabilities, and thus are unlikely to represent adaptations to the same selective environment. 
Even if it confers increased functional capabilities, a trait may not be favored by natural selection. To provide a fitness advantage, the enhanced capabilities must actually lead to an increase in survival or reproductive success. In some cases, increased functional capabilities may be irrelevant to an organism. Anolis lizards, for example, rarely jump as far as they can, so an increase in maximal jumping ability would seem to provide little benefit (Irschick and Losos, 1998). The best, and often only, way to investigate whether increased functional capabilities actually provide a fitness benefit is to study the organism in its natural environment (Greene, 1986; Hertz et al., 1988; Irschick and Garland, 2001).

The functional approach thus permits testing the hypothesis that convergent traits provide similar functional advantages in their shared environmental setting. This approach can be taken one step further by examining whether selection actually operates on differences in functional capacities, an approach that is increasingly accomplished (e.g., Irschick et al., 2008; Husak et al., 2009). Moreover, by examining the historical context in which a trait evolved, one can attempt to distinguish adaptation from exaptation by testing whether increased functional capacity is beneficial in the environment in which the trait evolved.

When Will Comparative Studies Fail to Identify Adaptations?

Even when natural selection has been the primary force driving evolution, correlative comparative studies may fail to identify adaptations. Classically, two simple reasons were put forth: species may adapt to the same selective pressure in different ways, or they may evolve the same phenotype to adapt to different selective pressures (Bock, 1977, 1980; Bock and Miller, 1959; Ridley, 1983). Recent conceptual developments, however, have added understanding of additional ways in which natural selection in similar environments can lead to adaptation, but not convergence.

Multiple Solutions to the Same Selective Problem

Multiple phenotypic solutions may exist to a given problem posed by the environment. For example, different fossorial rodent species dig with their forelegs, hindlegs, or teeth, with concomitant morphological differences (Fig. 2; Lessa, 1990; Stein, 2000). Similarly, predators confronting prey that contain toxic substances may evolve resistance or may avoid eating the part of the body that contains the toxin (see also Farrell et al. [1991] and Berenbaum and Zangerl [1992] on the vast variety of responses of herbivores to plant defenses). In the same manner, potential prey species may respond to the threat of predation by evolving greater crypticity, ability to flee, or ability to defend themselves (e.g., Losos et al., 2002). Tradeoffs among traits may also result in different phenotypes having equal fitness in a particular environment (Marks and Lechowicz, 2006). In all of these cases, comparative studies would not identify a relationship between occupation of a selective environment and evolution of a particular trait, even though all species had adapted to similar selective pressures, albeit in different ways.

Species may adapt in different ways to the same selective environment for a variety of reasons. Differences in their initial starting conditions - the phenotype, genetic variation and constraints present in the ancestral populations prior to exposure to the new selective contextmay cause evolution to proceed in different directions (Arnold, 1994; Donoghue, 2005). In addition, chance events, such as the order in which particular mutations occur, may also lead to different evolutionary outcomes (Mani and Clarke, 1990; Wichman et al., 1999; Ortlund et al., 2007; but see Weinreich et al. [2006]). These are the contingencies of history so emphasized by Gould (2002). 


\section{Multiple Selective Advantages of a Single Trait}

Conversely, similar phenotypes may evolve in different environments. For example, among mammals large canine teeth probably evolved to aid in prey capture and consumption in some species, such as members of the Carnivora, but for defense in others, such as some primates and ungulates. Similarly, hawks and shrikes use their hooked beaks to capture prey, but the Australian shrike-tit uses a similar beak to rip bark off trees while searching for insects (Simpson, 1978). In both examples, the phenotypes are convergent in function (delivering an injurious bite in the former case, seizing and rending in the latter case), but the selective context differs greatly among species, so once again, a one-to-one interspecific relationship does not exist between phenotype and environment, and thus statistical analyses would fail to detect adaptive evolution.

\section{Lack of a One-to-One Relationship Between Phenotype and Function}

The phenotype->performance->environment framework reveals additional ways in which comparative studies can miss the mark. In particular, very different morphologies may produce similar functional capabilities. In recent years, biomechanicians have paid increasing attention to the phenomenon of many-to-one relationships between morphology and performance. The idea is simple: for any phenotypic system in which parts interact to produce a function, then the same functional outcome may be produced by different combinations of trait values for the different parts (Alfaro et al., 2004; Vanhooydonck et al., 2006; Wainwright, 2007; Young et al., 2010). For example, labrid fish with many different jaw structures can produce the same suction force (Fig. 3; Alfaro et al., 2005); similarly, herbivorous lizards do not converge in jaw shape, but nonetheless do converge in amount of force transmission produced during jaw closure (Stayton, 2006).

Note that the many-to-one phenomenon is different from the existence of multiple solutions to environmental problems discussed above. In the latter case, species adapt in different ways, i.e., moving to different peaks in the adaptive landscape metaphor. In the former case, by contrast, selection is favoring the same functional solution, but through different morphological means of producing the same functional outcome (Fig. 4). In other words, divergent morphologies produce convergent functional capabilities, thus precluding a relationship between phenotype and environment, even if traits have evolved adaptively in response to similar environmental conditions. In this case, of course, functional convergence could be identified even in the absence of phenotypic convergence (Fig. 4).

\section{Adaptation, Exaptation, and Phylogenetic Analyses}

We often think of convergent evolution in terms of examples like marsupial thylacines and placental wolves or toxic animals and their mimics, in which distantly related taxa have evolved to become extremely similar in appearance. However, in many cases in which clades are very different in phenotype, natural selection may cause two species to become more similar to each than were their ancestors, but not be of sufficient magnitude to obliterate the pre-existing differences that occur among clades. Herrel et al. (2004) refer to such examples as "incomplete convergence" and Stayton (2006) provides a geometric framework in which this is one type of convergent evolution. In this light, an alternative definition of convergent evolution might be "instances in which species independently evolve to become more similar to each other than 
were their ancestors." In situations of this sort, phylogenetic analysis allows the detection of incomplete convergent evolution that otherwise might not be apparent.

For example, the head shape of lizards primarily reflects phylogeny; members of the same family cluster together in a multivariate morphological space regardless of what they eat. However, phylogenetic analysis indicates that across many clades, herbivorous species have become more similar to each other compared to the similarity among their carnivorous sister taxa (Fig. 5; herbivory is likely the derived state in these clades [Stayton, 2006]). A somewhat similar situation occurs with the evolution of longer limbs in rock-dwelling lizards in a number of clades (Revell et al., 2007b; but see Goodman and Isaac, 2008). In both cases, evolutionary change has occurred in similar ways in species independently utilizing the same selective conditions, but the resulting changes have not been great enough to override pre-existing interclade differences.

In cases such as these, we may ask why species do not converge completely. Possible explanations are that the optimal phenotype with respect to a given selective context may differ depending on the other characteristics of the species, that selective environments are not identical, that constraints preclude some lineages from attaining the optimal phenotype or that some species are still in the process of adapting (Stayton, 2006; Revell et al., 2007b; Hansen et al., 2008).

By the same token, phylogenetic analysis alone may miss evidence of exaptation. For example, rock-dwelling lizards have shallower heads than non-rock-dwellers, which presumably aids in utilization of crevices and movement on broad vertical surfaces (Revell et al., 2007b; Goodman and Isaac, 2008). However, phylogenetic analysis indicates that the transition to rockdwelling was not always accompanied by a decrease in head height (Revell et al., 2007b). In Anolis, for example, the head of the rock-dwelling $A$. bartschi is not particularly flat compared to related species. The reason is that most anoles are arboreal and have relatively flat heads, perhaps as an adaptation for moving on broad vertical surfaces. Anolis bartschi did not evolve a flatter head when it moved to a vertical, rocky habitat because its arboreal ancestors already possessed that trait. As a result, the flattened head of $A$. bartschi is an exaptation for rockdwelling, in contrast to the adaptive evolution of flat heads in other clades. Thus, even though rock-dwelling lizards tend to have flat heads, phylogenetic analysis alone would not pick up this trend; no correlation would exist between evolutionary transition to occupation of rocky habitats and evolutionary decrease in head height, because exapted species would not have evolved any difference when they moved into that habitat. Only by examining the phenotypes of extant taxa directly (i.e., aphylogenetically) would it become apparent that all rock dwellers have flat heads. Arnold (1994) provides a synthetic protocol for integrating historical and present-day approaches to distinguish exaptation from adaptation in comparative studies.

\section{Are Convergent Phenotypes Comparable Entities?}

Wenzel and Carpenter (1994) and Kluge $(2002,2005)$ have argued that comparative approaches are invalid because evolutionary changes are inherently unique historical events that cannot be treated as replicates in statistical analysis. Rather, each putative case of adaptation needs to be evaluated separately to assess whether a hypothesis of adaptation is supported. Kluge (2005) goes so far as to contend that the evolution of white feather and fur among Arctic species cannot be grouped as similar phenotypic responses to similar conditions. Even though all have evolved white coloration, Kluge argues, each case is unique; the evolution of white hair 
in the Arctic fox cannot be equated with the white pelage of the Arctic hare, nor to the white feathers of the ptarmigan.

This argument misses the point of adaptational analysis. Whether convergence represents "nothing more than error in the inference of homology" (Kluge, 2005) is irrelevant - the question is whether similar phenotypes have arisen in multiple taxa to perform similar functions in response to similar environmental conditions. In this context, it is straightforward to examine whether phenotypes in different taxa produce similar functional performance - if so, then they may have evolved in response to similar selective conditions; if not, then this hypothesis is falsified (Greene, 1986; Coddington, 1988; Pagel, 1994; Arnold, 1994; Losos and Miles, 1994). Thus, in the case of the white coloration of Arctic animals, it is easy enough to measure the spectral qualities of the pelage and to assess whether these colors provide enhanced crypsis, in comparison to the ancestral state, in the Arctic environment (Endler, 1984). Similarly, one can examine whether independently derived long legs in different clades provide similar increases in locomotor capabilities (Losos, 1990; Garland and Janis, 1993; Bauwens et al., 1995), and whether convergent features of any kind provide convergent enhanced performance. Similar phenotypes that evolved in different lineages may be historically unique, but their functional consequences are readily comparable.

Kluge (2005, p. 657) argues that there is "no language-independent standard of similarity with which to judge homoplasies as members of the same kind of convergence," but measures of performance provide the objective standards that Kluge seeks. For example, Kluge (2005) objects to considering the wings of birds and bats to be similar, yet clearly both provide the ability to fly, an ability not shared with their non-winged relatives.

\section{Genotypes, Phenotypes, Parallelism and Convergence}

Two perspectives have been taken concerning the relevance of convergent evolution to broader evolutionary issues. The first focuses on the adaptive significance of a trait, asking: has a particular trait evolved as an adaptation for something? This question arises not only because it is not always clear how or why a particular trait might have been favored by natural selection, but also from the criticisms raised against the "adaptationist programme" in the 1970's and 1980 's, leading to a widespread view in some quarters that natural selection is not nearly as pervasive as previously believed (Gould and Lewontin, 1979; Alberch, 1983; Wake and Larson, 1987; Goodwin, 1994; reviewed in Schwenk and Wagner, 2004). In this light, the observation that a trait has evolved independently multiple times in the same environmental context provides support for the hypothesis that natural selection has been responsible for evolution of the trait, with the caveats discussed above.

However, there is another perspective in which convergence is relevant to the study of natural selection. As part of the re-appraisal of the evolutionary primacy of natural selection, many workers argued that intrinsic constraints on the production of variation were as, or more, important than natural selection in shaping patterns of phenotypic diversity (reviewed in Gould, 2002; see Schwenk and Wagner [2004] for a more nuanced view). Put simply, is the uneven occupation of phenotypic space - the observation that many taxa are similar in phenotype, whereas some imaginable phenotypes (e.g., six limbed vertebrates) are never observed-the result of natural selection or of the inability of genetic and developmental systems to produce some types of variants?

$\underline{\text { Parallel Evolution and Natural Selection }}$ 
In this context, the issue of the underlying genetic and developmental basis for convergent traits becomes important. The distinction between convergent and parallel evolution is contentious (reviewed in Arendt and Reznick, 2007; Abouheif, 2008), in part because the terms predate modern concepts of genetics and development (Wake, 1999). As a result, numerous authors avoid the terms entirely, using phrases such as "phylogenetic replication" (Kopp, 2009) and "repeated evolution" (Gompel and Prud'homme, 2009). To avoid this quagmire, I have followed Arendt and Reznick (2007) in referring to all independently derived similarity as convergence (others avoid the controversy by using "homoplasy" to refer to all instances of independent evolution of traits that appear to be similar [Wake, 19991; Wake et al., 2011]).

The term "parallel evolution" is sometimes used to refer to convergent evolution achieved through the same genetic and developmental pathways, whereas non-parallel convergence refers to similar phenotypic outcomes achieved in different ways (part of the problem with parallel evolution is that this idea may be simple in concept, but actually delineating what constitutes the same pathway is extremely difficult). The occurrence of such parallel evolution suggests the possibility that the range of variation that can be produced may be limited or some variants may arise more often than others. Natural selection may be driving convergence, the argument goes, but internal constraints are biasing the options available; "better" solutions might be possible, but they are not attained due to such limitations (e.g., Wake, 1991; Futuyma et al., 1993; Shubin et al., 1995; Price and Pavelka, 1996; Gould, 2002; Schwenk and Wagner, 2004). By contrast, non-parallel convergence might suggest that natural selection has found the optimal solution for the problem posed by the environment.

Parsing the relative importance of variation-generating mechanisms and selection is not easy and requires detailed studies of both variation and selection. The importance of the former can be examined in several ways. The observation that a particular phenotype is never produced either within or among species - such as an even number of legs in adult centipedes (Arthur and Farrow, 1999) - suggests that the lack of species bearing that phenotype is a result of an intrinsic constraint, rather than selective disadvantage (the dichotomy between selection and constraint becomes fuzzy when one considers the possibility that variation arises during development, but the embryo cannot function and dies. Is this a developmental constraint on the production of variation or evidence of selection on an inferior phenotype? See Schwenk and Wagner [2004] for an enlightening discussion). Similarly, some comparative studies show that relatively little variation for a trait occurs intraspecifically and that derived traits are always present as variants in related species; these observations suggest that evolutionary change is biased by limitations on available variation, indicating a role for the variation-generating process in constraining evolutionary direction (Alberch, 1983; Wake and Larson, 1987). In addition, in cases dealing with quantitative traits, artificial selection studies can be used to test whether the lack of occurrence of a phenotype among extant species is the result of lack of ability to produce the necessary variation or lack of selection favoring that phenotype (Beldade et al., 2002; Fuller et al., 2005).

A complementary approach would be to focus on selection, rather than variation. Finding that convergent phenotypes in the same environment are produced by parallel mechanisms does not necessarily disprove the possibility that such phenotypes are selectively optimal in that environment (Hodin, 2000). To the extent that alternative phenotypes in some way may be created (e.g., by selective breeding [Beldade et al., 2002] or genetic manipulation in the laboratory [Poelwijk et al., 2007]), relative fitness or at least some measure of function can 
be measured to determine whether observed phenotypes truly are superior to others that might be created.

Parallel evolution has one additional implication for the inference of natural selection. Species that evolve similar traits by using similar developmental or genetic pathways are likely to share similar patterns of genetic covariation, as discussed above (Alberch, 1983). As a result, convergent evolution of a focal trait may occur not because selection favored that trait, but because it favored the same correlated trait in each species. By contrast, traits that evolve using distinct pathways are much less likely to share the same correlations. Hence, direct examination of whether natural selection favors the focal, convergent trait, as opposed to favoring a correlated trait, is particularly important for traits that have evolved in parallel.

Molecular Convergence, Adaptation, and Constraint

For more than a century, discussion of convergence by parallel evolution has focused on morphology. In the last few years, however, increasing attention has focused on the molecular level, examining the extent to which convergent phenotypes have evolved through changes in the same genes (reviewed in Gompel and Prud'Homme, 2009; Christin et al., 2010; Manceau et al., 2010; see also Kopp, 2009). On one hand, in a number of cases, very similar phenotypes have been shown to have arisen by very different molecular changes, such as the antifreeze glycoproteins of Arctic cod and Antarctic notothenioid fishes, which are nearly identical in structure and function, yet are derived from different genes (Chen et al., 1997). Such examples would seem to offer strong evidence of the unfettered ability of natural selection to build appropriate structures from diverse starting points.

On the other hand, recently there has been great fascination with the extent to which convergent traits are the result of mutations in the same gene and, even more so, by the same mutation in the same genes. Such molecular convergence is often taken as evidence for the existence of constraints on adaptive evolution (e.g., Christin et al., 2010; although the adaptive basis of some of these convergent phenotypes - e.g., spots on wings, missing trichomesremains to be established. Combined genetic and ecological research on the loss of lateral plates in sticklebacks is a model for how studies integrating selection and the molecular basis of phenotypic convergence can be integrated [Barrett et al., 2008]). The underlying reasoning is the same as that just discussed for parallel evolution, but with a twist. The similarity is the argument that repeated recruitment of the same gene or even the same mutation suggests the possibility of a bias in the way that variation is produced, thus constraining selection (Cooley and Willis, 2009; Chan et al., 2010). The twist results from the hierarchical nature of genetic variation (Fig. 6) - different (non-convergent) mutations in the same gene or mutations in different genes can have the same functional effects at the molecular level, and thus can produce a functionally equivalent change in development (e.g., Aminetzach et al., 2009; Rosenblum et al. 2010). In other words, parallel phenotypic evolution can result from non-convergent molecular evolution (Manceau et al., 2010).

Many examples exist of convergent phenotypes that, despite being affected by many genes, are produced by convergent changes in the same gene. Given this multiplicity of genetic options for mutations, why the same mutation occurs repeatedly to produce the convergent phenotype is an important question. Potential explanations include the size of the mutational target (larger genes or those with higher mutation rates are more likely to experience mutations), epistasis, and pleiotropy, among others (Kopp, 2009; Stern and Orgozozo, 2009; Christin et al., 2010; Gompert and Prud'Homme, 2010; Manceau et al., 2010). All of these possibilities would lead to the situation in which convergent phenotypes are produced in only a limited number of 
ways genetically (this situation could also have non-biological explanations, such as ascertainment and publication biases. Mc1r and dark pigment coloration is a prime example [Manceau et al., 2010]).. However, as with the previous discussion, the way to test whether convergence at the molecular level is indicative of constraint is to test this hypothesis directly by examining whether, in fact, variation is constrained, either by examining intra-population variation in the focal and related species to determine if other variants ever occur, or by conducting artificial selection experiments to see if phenotypic evolution can be produced and, if so, whether the same gene or mutation is always involved (e.g., Wichman et al., 1999; Lee et al., 2009; Lenski, 2009).

Of course, whether we consider convergence to be evidence of constraint in many cases depends on the scale at which the trait is examined. For example, the fact that the wings powering flight in vertebrates have been built in different ways in birds, pterosaurs, and bats might be taken as evidence for lack of constraint, yet all represent modified forelimbs and no vertebrate lineage has both forelimbs and wings, a combination that in theory could be very useful (e.g., Rowling, 1999). Thus, whatever genetic or developmental processes preclude the evolution of wings de novo may be viewed as a potential constraint on adaptive evolution in vertebrates. Similar examples of adaptive convergence shaped by constraint abound at the molecular level. For instance, the motor protein Prestin is present in outer hair cells in mammals and is important for hearing high frequency sounds. Cetaceans and bats have independently acquired 14 identical amino acid changes in Prestin, in many cases apparently changes from the same ancestral amino acid (Liu et al., 2010). These changes almost surely are adaptations involved in the evolution of echolocating capability in the two groups. Nonetheless, a possible role for constraint is also obvious. We would expect that the easiest evolutionary course to the evolution of echolocation would be modification of the pre-existing mammalian auditory system present in both groups, whereas a lineage evolving echolocation from a very different starting point very likely would come up with a different means of echolocation. Whales and bats are adept at echolocating - whether they might be even better had they not been shackled by their mammalian heritage is unknown. Thus, to some extent, constraint is in the eye of the beholder. Because evolution is descent with modification (Darwin, 1859), all evolutionary change is constructed from what previously has evolved, which inevitably makes some changes more likely than others (Jacob, 1977).

A short review cannot possibly cover all the interesting possibilities being revealed by genomic analysis. For example, even examples of convergent phenotypes built from different molecular precursors - such as the identical skin toxins independently derived in two frog lineages from different hormone genes - may involve a suggestion of constraint if the different genes are themselves the result of ancient gene duplications and thus retain some ancestral similarity in structure (Roelants et al., 2010; see also Zhang, 2003; Hoffman et al., 2010). This situation, in turn, is reminiscent of other examples of deep homology, in which clearly nonhomologous, convergent phenotypic structures (e.g., eyes of mollusks, vertebrates, and invertebrates) have evolved by means of very similar changes in the same development genes (Shubin et al., 2009). Examples such as these reveal that no necessary relationship exists between convergence at the phenotypic and genotypic levels, and that parsing the relative roles of natural selection and constraint in determining the extent and form of biological diversity can be context-dependent and at times subjective (see Schwenk and Wagner, 2004; Wake et al., 2011). 


\section{Conclusions}

As in so many other ways, Darwin was prescient 150 years ago when he identified convergence as a common outcome of natural selection operating on species occupying similar environments. And, as in so many other ways, these are exciting times in evolutionary biology, as we now have the means to identify the genetic bases of phenotypic convergence, as well as the ability to study - sometimes even experimentally - natural selection in the field. Convergent evolution, even in similar environments, is not always indicative of natural selection operating on the focal phenotype, and natural selection operating in the same way can fail to produce convergence in different lineages. Nonetheless, the occurrence of convergence mandates that adaptive explanations and their underlying mechanisms be investigated. Now, more than ever, we have the tools to do so, and in ways that could not have been imagined even a few years ago.

Acknowledgments

For very helpful comments on previous versions of this manuscript, I thank R. Barrett, P. Gorring, H. Greene, J. Hanken, H. Hoekstra, M. Olson, T. Stayton and D. Wake, and for assistance in figure preparation, I thank M. Alfaro, B. Stein, P. Wainwright and M. Woolley. 


\section{Literature Cited}

Abouheif, E. 2008. Parallelism as the pattern and process of mesoevolution. Evol. Dev. 10:3-5.

Alberch, P. 1983. Morphological variation in the neotropical salamander genus Bolitoglossa. Evolution 37:906-919.

Alberch, P., and E. A. Gale. 1985. A developmental analysis of an evolutionary trend - digital reduction in amphibians. Evolution 39:8-23.

Alfaro, M. E., D. I. Bolnick, and P. C. Wainwright. 2004. Evolutionary consequences of redundant design in labrid fishes. Integr. Comp. Biol. 44:514-514.

Alfaro, M. E., D. I. Bolnick, and P. C. Wainwright. 2005. Evolutionary consequences of manyto-one mapping of jaw morphology to mechanics in labrid fishes. Am. Nat. 165:E140E154.

Aminetzach, Y. T., J. R. Srouji, C. Y. Kong, and H. E. Hoekstra. 2009. Convergent evolution of novel protein function in shrew and lizard venom. Curr. Biol. 19:1925-1931.

Amundson, R. 2001. Adaptation, development, and the quest for common ground. Pp. 303-334 in S. H. Orzack, and E. Sober, eds. Adaptation and optimality. Cambridge Univ. Press, Cambridge, UK.

Arendt, J., and D. Reznick. 2007. Convergence and parallelism reconsidered: what have we learned about the genetics of adaptation? Trends Ecol. Evol. 23:26-32.

Arnold, E. N. 1994. Investigating the origins of perfomance advantage: adaptation, exaptation and lineage effects. Pp. 123-168 in P. Eggleton and R. I. Vane-Wright, eds. Phylogenetics and ecology. Adademic Press, New York.

Arnold, S. J. 1983. Morphology, performance and fitness. Am. Zool. 23:347-361.

Arthur, W., and M. Farrow. 1999. The pattern of variation in centipede segment number as an example of developmental constraint in evolution. J. Theor. Biol. 200:183-191.

Autumn, K., M. Sitti, Y. C. A. Liang, A. M. Peattie, W. R. Hansen, S. Sponberg, T. W. Kenny, R. Fearing, J. N. Israelachvili, R. J. Full. 2002. Evidence for van der Waals adhesion in gecko setae. Proc. Natl. Acad. Sci. USA 99:12252-12256.

Barrett, R. D. H., S. M. Rogers, and D. Schluter. 2008. Natural selection on a major armor gene in threespine stickleback. Science 322:255-257.

Bauwens, D., T. Garland, A. M. Castilla, and R. Vandamme. 1995. Evolution of sprint speed in lacertid lizards - morphological, physiological, and behavioral covariation. Evolution 49:848-863.

Beldade, P., K. Koops, and P. M. Brakefield. 2002. Developmental constraints versus flexibility in morphological evolution. Nature 416:844-847.

Berenbaum, M. R., and A. R. Zangerl. 1992. Genetics of physiological and behavioral resistance to host furanocoumarins in the parsnip webworm. Evolution 46:1373-1384.

Blount, Z. D., C. Z. Borland, and R. E. Lenski. 2008. Historical contingency and the evolution of a key innovation in an experimental population of Escherichia coli. Proc. Natl. Acad. Sci. U.S.A. 105:7899-7906. 
Bock, W. J. 1977. Adaptation and the comparative method. Pp. 57-82 in M. K. Hecht, P. C. Goody, and B. Hecht, eds. Major patterns in vertebrate evolution. Plenum Press, New York.

Bock, W. J. 1980. The definition and recognition of biological adaptation. Am. Zool. 20:217227.

Bock, W. J. and W. D. Miller. 1959. The scansorial foot of the woodpeckers, with comments on the evolution of perching and climbing feet in birds. Am. Mus. Novit. 1931:9-45.

Carvalho, P., J. A. Felizola Diniz-Filho, and L. M. Bini. 2006. Factors influencing changes in trait correlations across species after using phylogenetic independent contrasts. Evol. Ecol. 20:591-602.

Chan, Y. F., M. E. Marks, F. C. Jones, G. Villareal, Jr., M. D. Shapiro, S. D. Brady, A. M. Southwick, D. M. Absher, J. Grimwood, J. Schmutz, R. M. Myers, D. Petrov, B. Jønsson, D. Schluter, M. A. Bell, and D. M. Kingsley. 2010. Adaptive evolution of pelvic reduction in sticklebacks by recurrent deletion of a Pitxl enhancer. Science 327:305-305.

Chen, L. B., A. L. DeVries, and C. H. C. Cheng. 1997. Convergent evolution of antifreeze glycoproteins in Antarctic notothenioid fish and Arctic cod. Proc. Natl. Acad. Sci. USA 94: 3817-3822.

Christin, P. A., D. M. Weinreich, and G. Besnard. 2010. Causes and evolutionary significance of genetic convergence. Trends Genet. 26:400-405.

Coddington, J. A. 1988. Cladistic tests of adaptational hypotheses. Cladistics 4:3-22.

Conway Morris, S. 2003. Life's solution: inevitable humans in a lonely universe. Cambridge Univ. Press, Cambridge, UK.

Conway Morris, S. 2009. Evolution and convergence: some wider considerations. Pp. 46-67 in S. C. Morris, ed. The deep structure of biology: Is convergence sufficiently ubiquitous to give a directional signal? Templeton Foundation Press, West Conshohocken, Pennsylvania.

Conway Morris, S. 2010. Darwin at the edge of the visible universe. EMBO Rep. 11:898.

Cooley, A. M., and J. H. Willis. 2009. Genetic divergence causes parallel evolution of flower color in Chilean Mimulus. New Phytol. 183:729-739.

Darwin, C. 1859. On the origin of species by means of natural selection, or, The preservation of favoured races in the struggle for life. John Murray, London, UK.

Donoghue, M. J. 2005. Key innovations, convergence, and success: macroevolutionary lessons from plant phylogeny. Paleobiology 31:77-93.

Eldredge. N., and J. Cracraft. 1980. Phylogenetic patterns and the evolutionary process: method and theory in comparative biology. Columbia Univ. Press, New York.

Elena, S. F, and R. Sanjuán. 2007. Virus evolution: insights from an experimental approach. Ann. Rev. Ecol. Evol. Syst. 38:27-52.

Endler, J. A. 1980. Natural selection on color patterns in Poecilia reticulata. Evolution 34:76-91.

Endler, J. A. 1984. Progressive background in moths, and a quantitative measure of crypsis. Biol. J. Linn. Soc. 22:187-231.

Endler, J. A. 1986. Natural selection in the wild. Princeton Univ. Press, Princeton, N.J.

Farrell, B. D., D. E. Dussourd, and C. Mitter. 1991. Escalation of plant defense - do latex and resin canals spur plant diversification? Am. Nat. 138:881-900.

Felsenstein, J. 1985. Phylogenies and the Comparative Method. Am. Nat. 125:1-15.

Felsenstein, J. 2004. Inferring phylogenies. Sinauer Associates, Sunderland, MA. 
Fuller, R. C., C. F. Baer, and J. Travis. 2005. How and when selection experiments might actually be useful. Integr. Comp. Biol. 45: 391-404.

Futuyma, D. J., M. C. Keese and S. J. Scheffer. 1993. Genetic constraints and the phylogeny of insect-plant associations - responses of Ophraella communa (Coleoptera, Chrysomelidae) to host plants of its congeners. Evolution 47:888-905.

Garland, T., A. F. Bennett, and E. L. Rezende. 2005. Phylogenetic approaches in comparative physiology. J. Exp. Biol. 208:3015-3035.

Garland, T., and C. M. Janis. 1993. Does metatarsal femur ratio predict maximal running speed in cursorial mammals. J. Zool. 229:133-151.

Gittleman, J. L. 1981. The phylogeny of parental care in fishes. Anim. Behav. 29:936-941.

Gompel. N., and B. Prud'homme. 2009. The causes of repeated genetic evolution. Dev. Biol. 332:36-47.

Goodman, B. A., and J. L. Isaac. 2008. Convergent body flattening in a clade of tropical rockusing lizards (Scincidae : Lygosominae). Biol. J. Linn. Soc. 94:399-411.

Goodwin, B. 1994. How the leopard changed its spots: the evolution of complexity. Weidenfeld \& Nicolson, London, UK.

Gould, S. J. 2002. The structure of evolutionary theory. Belknap Press of Harvard Univ. Press, Cambridge, MA.

Gould, S. J., and R. C. Lewontin. 1979. Spandrels of San Marco and the Panglossian Paradigm a critique of the Adaptationist Program. Proc. R. Soc. Lond. B Biol. Sci. 205:581-598.

Gould, S. J., and E. S. Vrba. 1982. Exaptation - a missing term in the science of form. Paleobiology 8:4-15.

Grandcolas, P., and C. D'haese. 2003. Testing adaptation with phylogeny: how to account for phylogenetic pattern and selective value together. Zool. Scr. 32:483-490.

Greene, H. W. 1986. Natural history and evolutionary biology. Pp. 99-108 in M. E. Feder and G. V. Lauder, eds. Predator-prey relationships: perspectives and approaches from the study of lower vertebrates. Univ. of Chicago Press, Chicago, IL.

Hansen, T. F., J. Pienaar, and S. H. Orzack. 2008. A comparative method for studying adaptation to a randomly evolving environment. Evolution 62:1965-1977.

Harvey, P. H., and M. D. Pagel. 1991. The comparative method in evolutionary biology. Oxford Univ. Press, Oxford, UK.

Herrel, A., B. Vanhooydonck, and R. Van Damme. 2004. Omnivory in lacertid lizards: adaptive evolution or constraint? J. Evol. Biol. 17:974-984.

Hertz, P. E., R. B. Huey, and T. Garland. 1988. Time budgets, thermoregulation, and maximal locomotor performance - are reptiles olympians or boy scouts. Am. Zool. 28:927-938.

Hildebrand, M. 1985. Walking and running. Pp. 38-57 in M. Hildebrand, D. M. Bramble, K. F. Liem, and D. B. Wake, eds. Functional vertebrate morphology. Belknap Press, Cambridge, MA.

Hodin, J. 2000. Plasticity and constraints in development and evolution. J. of Exp. Zool. 288:120.

Hoffmann, F. G., J. C. Opazo, and J. F. Storz. 2010. Gene cooption and convergent evolution of oxygen transport hemoglobins in jawed and jawless vertebrates. Proc. Natl. Acad. Sci. USA 107:14274-14279.

Huey, R. B., and A. F. Bennett. 1987. Phylogenetic studies of coadaptation - preferred temperatures versus optimal performance temperatures of lizards. Evolution 41:10981115. 
Husak, J.F., A. K. Lappin, and R. A. Van Den Bussche. 2009. The fitness advantage of a highperformance weapon. Biol. J. Linn. Soc. 96:840-845.

Irschick, D. J., J. J. Meyers, J. F. Husak, and J. F. Le Galliard. 2008. How does selection operate on whole-organism functional performance capacities? A review and synthesis. Evol. Ecol. Res. 10:177-196.

Irschick, D. J., and T. Garland Jr. 2001. Integrating function and ecology in studies of adaptation: investigations of locomotor capacity as a model system. Annu. Rev. Ecol. Syst. 32:367396.

Irschick, D. J., and J. B. Losos. 1998. A comparative analysis of the ecological significance of maximal locomotor performance in Caribbean Anolis lizards. Evolution 52:219-226.

Ives, A. R., P. E. Midford, and T. Garland. 2007. Within-species variation and measurement error in phylogenetic comparative methods. Syst. Bio. 56:252-270.

Jacob, F. 1977. Evolution and tinkering. Science 196:1161-1166.

Jaekel, M., and D. B. Wake. 2007. Developmental processes underlying the evolution of a derived foot morphology in salamanders. Proc. Natl. Acad. Sci. USA. 104:20437-20442.

Kassen, R. Toward a general theory of adaptive radiation: insights from microbial experimental evolution. Ann. N.Y. Acad. Sci. 1168:3-22.

Kluge, A. G., 2002. Distinguishing "or" from "and" and the case for historical identification. Cladistics 18:585-593.

Kluge, A. G. 2005. Testing lineage and comparative methods for inferring adaptation. Zool. Scr. 34:653-663

Kopp, A. 2009. Metamodels and phylogenetic replication: a systematic approach to the evolution of developmental pathways. Evolution 63:2771-2789.

Lande. R., and S. J. Arnold. 1983. The measurement of selection on correlated characters. Evolution 37:1210-1226.

Lauder, G. V. 1981. Form and function: structural analysis in evolutionary morphology. Paleobiology 7:430-442.

Lee, M.-C., H.-H. Chou, and C.J. Marx. 2009. Asymmetric, bimodal trade-offs during adaptation of Methylobacterium to distinct growth substrates. Evolution 63:2861-2830.

Lenski, R. E. 2009. Chance and necessity in evolution. Pp. 3-16 in S. C. Morris, ed. The deep structure of biology: Is convergence sufficiently ubiquitous to give a directional signal? Templeton Foundation Press, West Conshohocken, Pennsylvania.

Leroi, A. M., M. R. Rose, and G. V. Lauder. 1994. What does the comparative method reveal about adaptation. Am. Nat. 143:381-402.

Lessa, E. P. 1990. Morphological evolution of subterranean mammals: integrating structural, functional, and ecological perspectives. Pp. 211-230 in E. Nevo, and O.A. Reig, eds. Progress in clinical and biological research, vol. 335. Wiley-Liss, New York.

Liu, Y., J. A. Cotton, B. Shen, X. Q. Han, S. J. Rossiter, and S. Y. Zhang. 2010. Convergent sequence evolution between echolocating bats and dolphins. Curr. Biol. 20:R53-R54.

Losos, J. B. 1990. The evolution of form and function - morphology and locomotor performance in West-Indian Anolis lizards. Evolution 44:1189-1203.

Losos, J. B., and D. B. Miles. 1994. Adaptation, constraint, and the comparative method: phylogenetic issues and methods. Pp. 60-98 in P. C. Wainwright and S. Reilly, eds. Ecological morphology: integrative organismal biology. Univ. of Chicago, Chicago, IL.

Losos, J. B., P. L.N. Mouton, R. Bickel, I. Cornelius, and L. Ruddock. 2002. The effect of body armature on escape behaviour in cordylid lizards. Anim. Behav. 64:313-321. 
Manceau. M., V. S. Domingues, C. R. Linnen, E. B. Rosenblum, and H. E. Hoekstra. 2010. Convergence in pigmentation at multiple levels: mutations, genes and function. Philos. Trans. R. Soc. Lond. B Biol. Sci. 365: 2439-2450.

Mani, G. S., and B. C. Clarke. 1990. Mutational order - a major stochastic process in evolution. Proc. R. Soc. Lond. B Biol. Sci. 240:29-37.

Marks, C. O., and M. J. Lechowicz. 2006. Alternative designs and the evolution of functional diversity. Am. Nat. 167:55-66.

Maynard Smith, J., R. Burian, S. Kauffman, P. Alberch, J. Campbell, B. Goodwin, R. Lande, D. Raup, and L. Wolpert. 1985. Developmental constraints and evolution. Q. Rev. Biol. 6:265-287.

Mayr, E. 1963. Animal Species, Evolution, and Geographic Isolation. Reply. Syst. Zool. 12:204206.

Ortlund, E. A., J. T. Bridgham, M. R. Redinbo, and J. W. Thornton. 2007. Crystal structure of an ancient protein: evolution by conformational epistasis. Science 317:1544-1548.

Pagel, M. 1994. Detecting correlated evolution on phylogenies - a general method for the comparative analysis of discrete characters. Proc. R. Soc. B 255:37-45.

Pagel, M. D., and P. H. Harvey. 1989. Comparative methods for examining adaptation depend on evolutionary models. Folia Primatol. 53:203-220.

Poelwijk, F. J., D. J. Kiviet, D. M. Weinreich, and S. J. Tans. 2007. Empirical fitness landscapes reveal accessible evolutionary paths. Nature 445:383-386.

Price, T., and M. Pavelka. 1996. Evolution of a colour pattern: history, development, and selection. J. of Evol. Biol. 9:451-470.

Reeve, H. K., and P. W. Sherman. 1993. Adaptation and the goals of evolutionary research. Q. Rev. Biol. 68:1-32.

Reich, P. B., M. B. Walters, and D. S. Ellsworth. 1997. From tropics to tundra: global convergence in plant functioning. Proc. Natl. Acad. Sci. USA 94:13730-13734.

Revell, L. J., L. J. Harmon, R. B. Langerhans, J. J. Kolbe. 2007a. A phylogenetic approach to determining the importance of constraint on phenotypic evolution in the neotropical lizard Anolis cristatellus. Evol. Ecol. Res. 9:261-282.

Revell, L. J., M. A. Johnson, J. A. Schulte, J. J. Kolbe, and J. B. Losos. 2007b. A phylogenetic test for adaptive convergence in rock-dwelling lizards. Evolution 61:2898-2912.

Reznick, D. N., and C. K. Ghalambor. 2005. Selection in nature: experimental manipulations of natural populations. Integr. Comp. Biol. 45:456-462.

Ridley, M. 1983. The explanation of organic diversity: the comparative method and adaptations for mating. Oxford Univ. Press, Oxford, UK.

Roelants ,K., B. G. Fry, J. A. Norman, E. Clynen, L. Schoofs, and F. Bossuyt. 2010. Identical skin toxins by convergent molecular adaptation in frogs. Curr. Biol. 20:125-130.

Rosenblum, E. B., H. Römpler, T. Schöneberg and H. E. Hoekstra. 2010. The molecular and functional basis of phenotypic convergence in white lizards at White Sands. Proc. Natl. Acad. Sci. U.S.A. 107:2113-2117.

Rowling. J. K. 1999. Harry Potter and the prisoner of Azkaban. Arthur A. Levine Books, New York.

Schluter, D. 1996. Adaptive radiation along genetic lines of least resistance. Evolution 50:17661774.

Schluter, D. 2000. The ecology of adaptive radiation. Oxford Univ. Press, Oxford, UK. 
Schwenk, K., and G. P. Wagner. 2004. The relativism of constraints on phenotypic evolution. Pp. 390-408 in M. Pigliucci and K. Preston, eds. Phenotypic integration: studying the ecology and evolution of complex phenotypes. Oxford Univ. Press, Oxford, UK.

Shubin, N., C. Tabin, and S. Carroll. 2009. Deep homology and the origins of evolutionary novelty. Nature 457:818-823.

Shubin, N., D. B. Wake, and A. J. Crawford. 1995. Morphological variation in the limbs of Taricha granulosa (Caudata, Salamandridae) - evolutionary and phylogenetic implications. Evolution 49:874-884.

Simpson, G. G. 1953. The major features of evolution. Columbia Univ. Press, New York.

Simpson, G. G. 1978. Variation and details of macroevolution. Paleobiology 4:217-221.

Stayton, C. T. 2006. Testing hypotheses of convergence with multivariate data: morphological and functional convergence among herbivorous lizards. Evolution 60:824-841.

Stayton, C. T. 2008. Is convergence surprising? An examination of the frequency of convergence in simulated datasets. J. Theor. Biol. 252:1-14

Stebbins, G. L. 1974. Flowering plants: evolution above the species level. Belknap Press of Harvard Univ. Press, Cambridge, MA.

Stein, B. E. 2000. Morphology of subterranean rodents. Pp. 19-61 in E. A. Lacey, J. L. Patton, and G. N. Cameron, eds. Life underground: the biology of subterranean rodents. The Univ. of Chicago Press, Chicago, IL.

Stern, D. L., and V. Orgogozo. 2009. Is genetic evolution predictable? Science 323:746-751.

Vanhooydonck, B., A. Herrel, R. Van Damme, and D. J. Irschick. 2006. The quick and the fast: the evolution of acceleration capacity in Anolis lizards. Evolution 60:2137-2147.

Wainwright, P. C. 2007. Functional versus morphological diversity in macroevolution. Annu. Rev. Ecol. Syst. 38:381-401.

Wainwright, P. C., and S. M. Reilly. 1994. Ecological morphology: integrative organismal biology. Univ. Chicago Press, Chicago, IL.

Wake, D. B. 1991. Homoplasy - the result of natural selection, or evidence of design limitations. Am. Nat. 138:543-567.

Wake, D. B. 1999. Homoplasy, homology and the problem of 'sameness' in biology. Pp. 24-46 in G. R. Bock and G. Cardew, eds. Homology. Novartis Foundation Symposium 222. John Wiley \& Sons, New York.

Wake, D. B., M. H. Wake, and C. D. Specht. 2011. Homoplasy: from detecting pattern to determining process and mechanism of evolution. Science, in press.

Wake, D. B., and A. Larson. 1987. Multidimensional analysis of an evolving lineage. Science 238:42-48.

Weinreich, D. M., N. F. Delaney, M. A. DePristo, and D. L. Hartl. 2006. Darwinian evolution can follow only very few mutational paths to fitter proteins. Science 312:111-114.

Wenzel, J. W., and J. M. Carpenter. 1994. Comparing methods: adaptive traits and tests of adaptation. Pp. 79-101 in P. Eggleton and R. I. Vane-Wright, eds. Phylogenetics and Ecology. Academic Press, New York.

Wichman, H. A., M. R. Badgett, L. A. Scott, C. M. Boulianne, and J. J. Bull. 1999. Different trajectories of parallel evolution during viral adaptation. Science 285:422-424.

Wichman, H. A., and C. J. Brown. 2010. Experimental evolution of viruses: Microviridae as a model system. Phil. Trans. Royal Soc. Lond. B 365:2495-2501. 
Young, R. L., M. J. Sweeney, and A. V. Badyaev. 2010. Morphological diversity and ecological similarity: versatility of muscular and skeletal morphologies enables ecological convergence in shrews. Funct. Ecol. 24:556-565.

Zhang, J. Z. 2003. Parallel functional changes in the digestive RNases of ruminants and colobines by divergent amino acid substitutions. Mol. Biol. Evol. 20:1310-1317. 
Figure 1. Convergence resulting from random evolution. In a simulation, traits evolved according to Brownian Motion and speciation occurred according to a pure birth Yule process of cladogenesis (Stayton, 2008). The result is that some evolved to become more phenotypically similar than were their ancestors (e.g., species A and G, and B and E). R represents the phenotype of the ancestor (root). Figure modified from Stayton (2008).
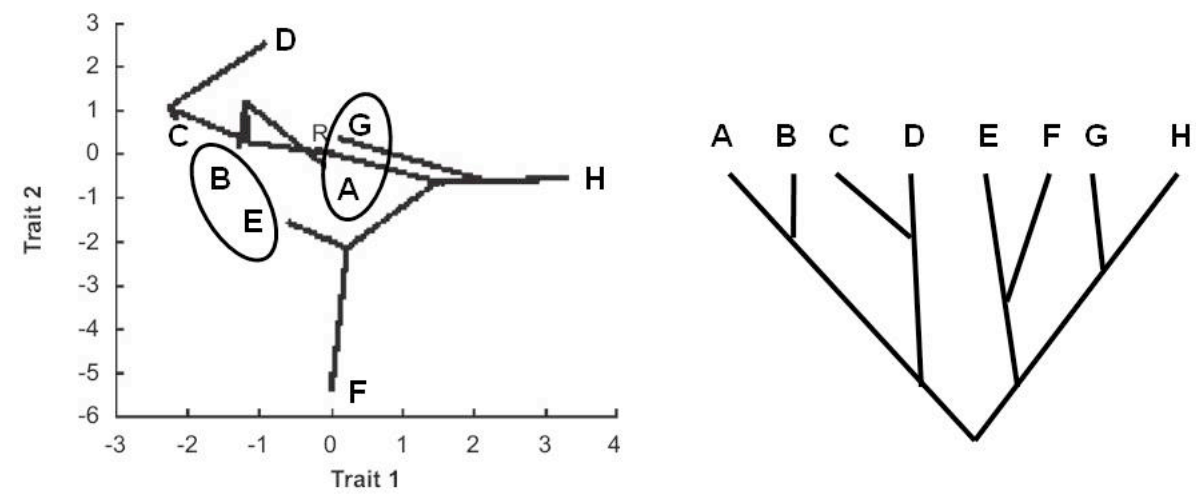
Figure 2. Skulls and feet of three species that dig burrows in different ways. From Stein (2000).

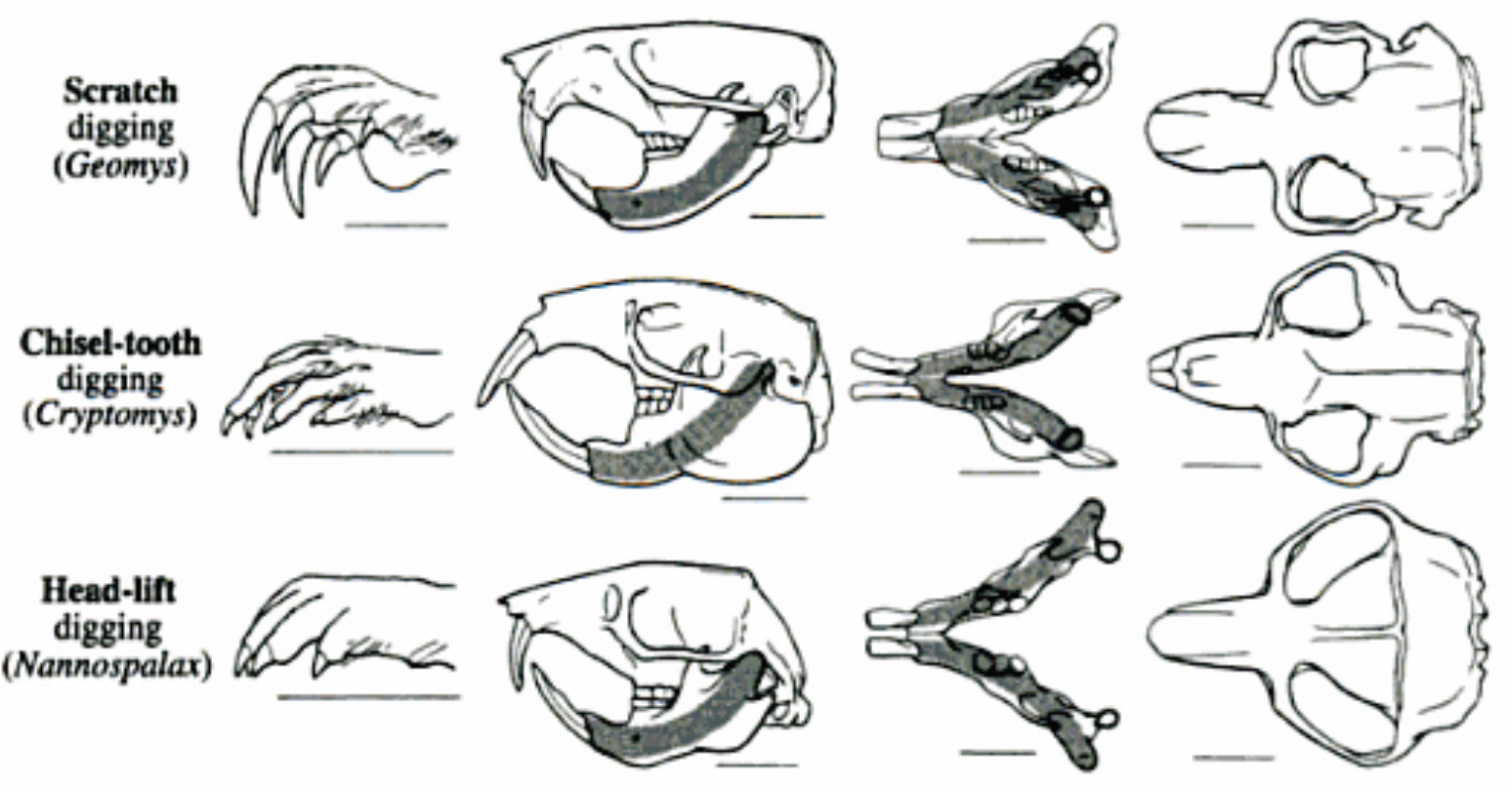


Figure 3.

Many-to-one Morphology-to-Performance Mapping. Labrid fish have highly kinetic heads and jaw protrusion is affected by four linked bony elements. The three-dimensional surface illustrates the different combinations of jaw, maxilla, and nasal length (all scaled in proportion to the positionally fixed head element) that produce the same biomechanical performance in jaw protrusion. Figure on left from Wainwright et al., 2005; figure on right from Alfaro et al., 2005.
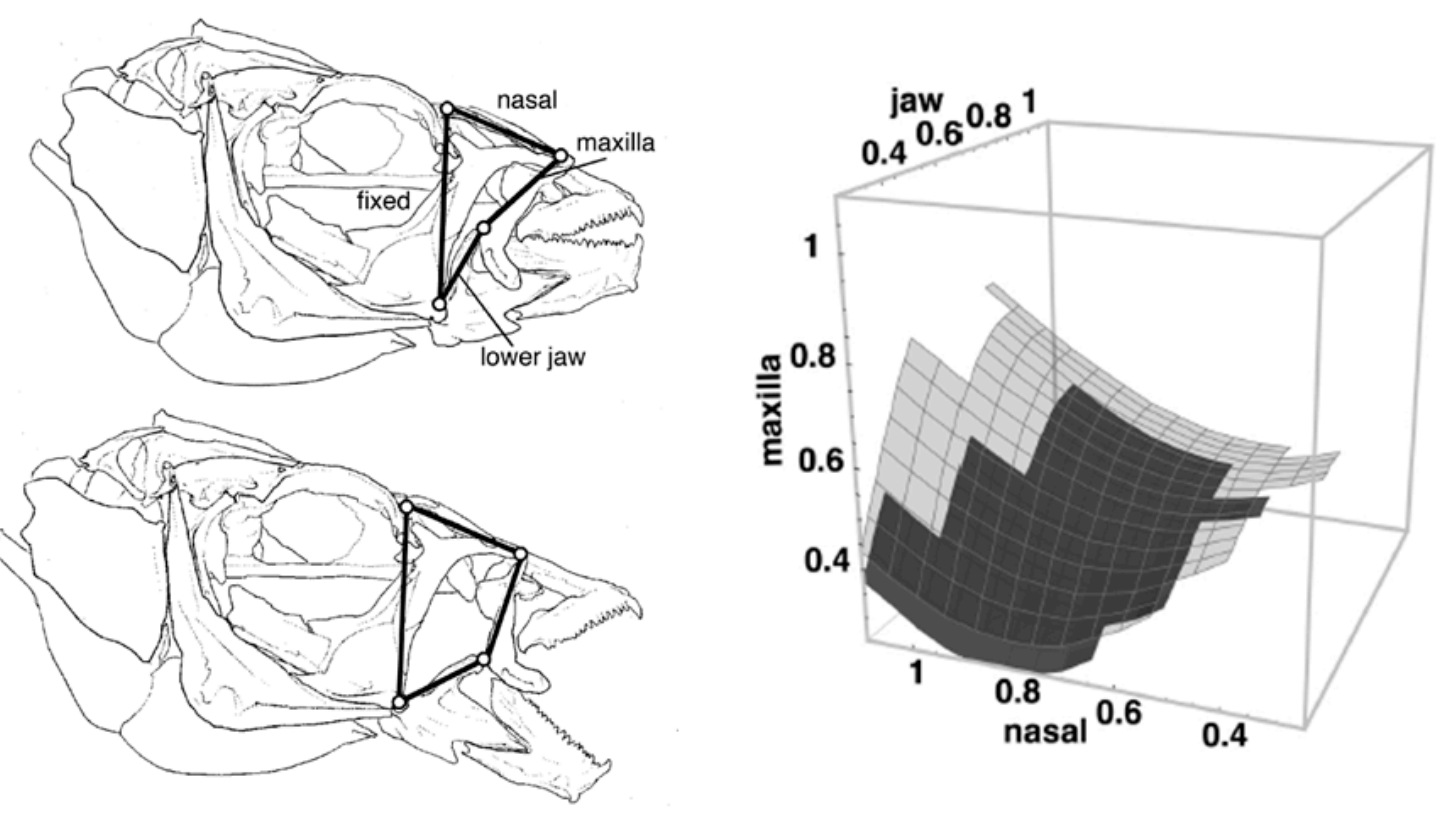
Figure 4. Many-to-one Morphology-Performance Relationships and Convergence. (a) If there is a direct, linear relationship between morphology and performance, then selection for a particular performance ability will lead to convergent evolution of similar morphology in multiple taxa. (b) By contrast, when many-to-one relationships exist, then convergent evolution in performance capability may occur by non-convergent evolution of morphology. From Losos (2009).

(a)

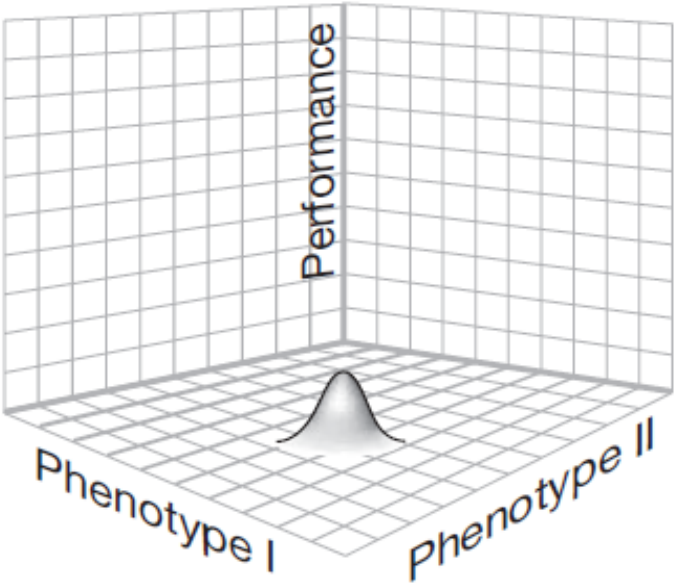

(b)

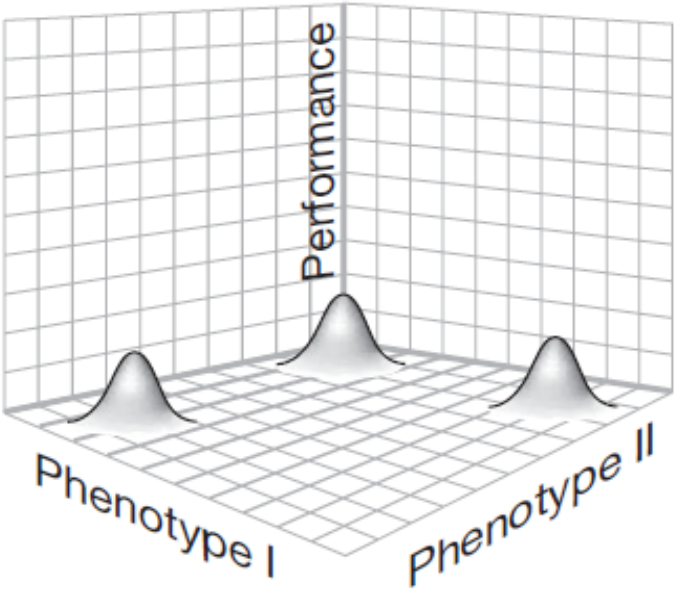


Figure 5. Convergent evolutionary changes may not erase differences among clades. In lizards, the evolution of herbivory usually leads to evolutionary change in morphology in the same direction, as indicated by the direction of the vector. However, these changes are not sufficient to override among-clade differences. Axes represent different aspects of head morphology, as analyzed using geometric morphometric methods. Figure from Stayton, 2006.

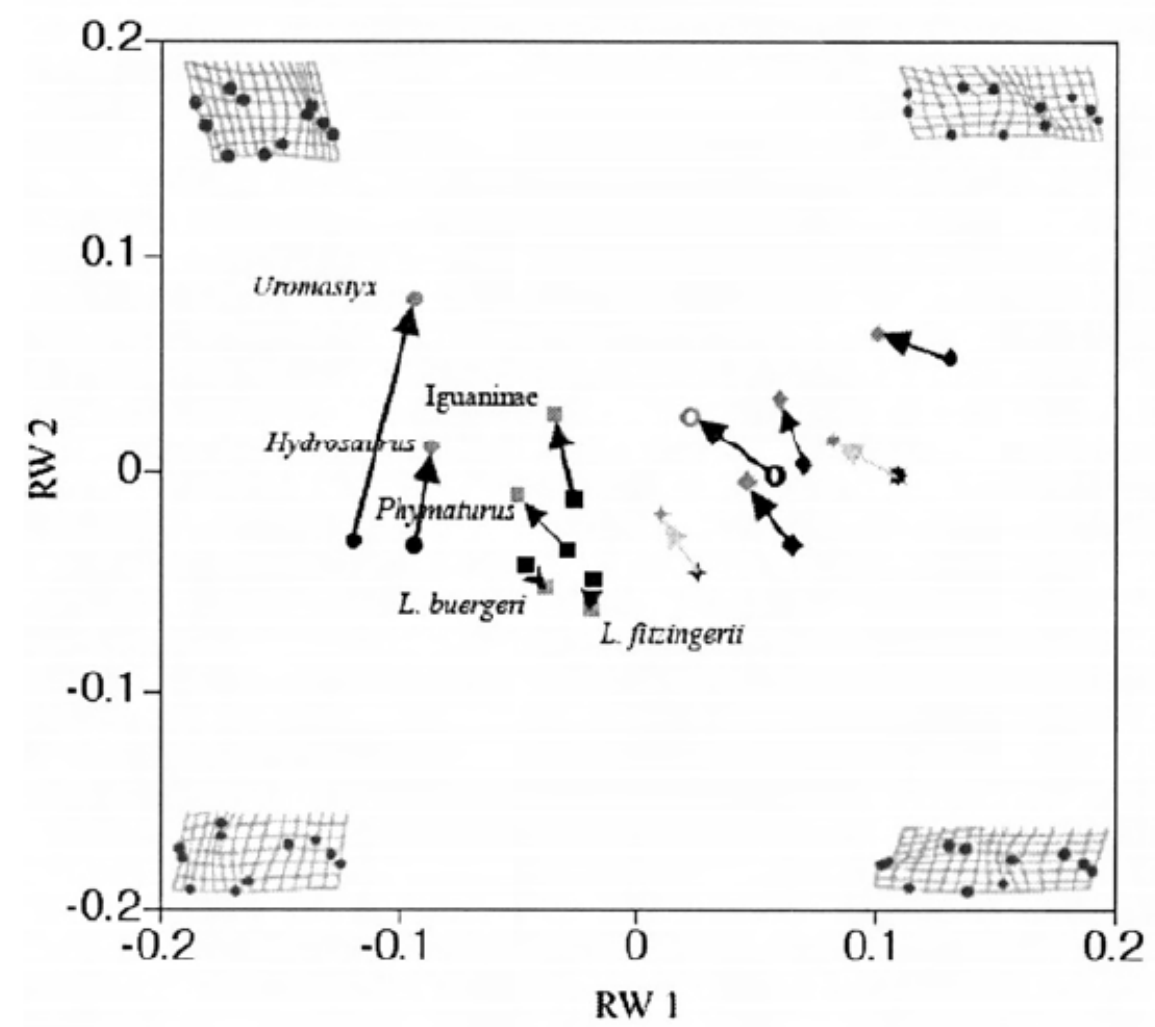


Figure 6. Non-Convergence at lower hierarchical levels produces convergence at higher levels. a) Many-to-one mapping of performance to morphology results in convergence in performance, but not in phenotype; b) Non-convergent developmental changes produce convergent phenotypes; c) Mutations in different genes produce convergent changes in development; d) Different functional changes within the same gene produce convergent change in development; e) Different mutations in the same gene produce convergent change in gene function; f) convergent mutational change produces convergent changes at all hierarchical levels.

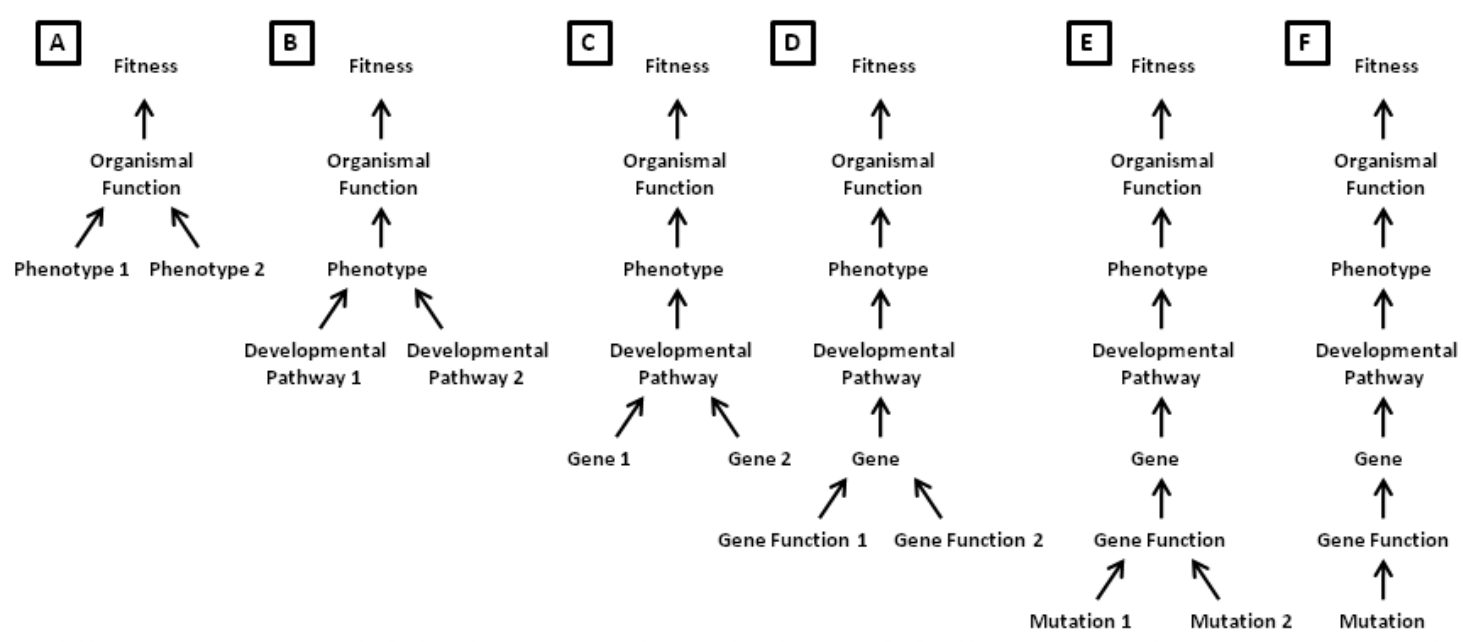

